\title{
The Mechanism of Centrally Mediated Cardiovascular Actions of the Three Structurally Different Calcium Antagonists, Verapamil, Diltiazem and Nicardipine, in Rats
}

\author{
Yutaka Imai, Keishi Abe, Shuichi Sasaki, Naoyoshi \\ Minami, Masahide Seino, Kaoru Yoshinaga and Norio \\ TAIRA* \\ The Second Department of Internal Medicine and \\ *Department of Pharmacology, Tohoku University School \\ of Medicine, Sendai 980
}

Imai, Y., Abe, K., Sasaki, S., Minami, N., Seino, M., Yoshinaga, K. and TaIra, N. The Mechanism of Centrally Mediated Cardiovascular Actions of the Three Structurally Different Calcium Antagonists, Verapamil, Diltiazem and Nicardipine, in Rats. Tohoku J. exp. Med., 1987, 151 (1), 65-80 — Centrally mediated cardiovascular effects of the three structurally different calcium antagonists (Ca-antagonists), i.e., verapamil, diltiazem and nicardipine, were studied in rats. In conscious rats, when administered intracerebroventricularly (i.c.v.) in doses of $0.3,1$ and $3 \mu \mathrm{g} / \mathrm{kg} / \mathrm{min}$ for $30 \mathrm{~min}$, all the three Ca-antagonists induced dose-dependent increases in mean arterial pressure (MAP) and pulse rate (PR), whereas nicardipine administered intravenously (i.v.) caused a decrease in MAP and an increase in PR. In anesthetized rats all the three $\mathrm{Ca}$-antagonists in a dose of $3 \mu \mathrm{g} / \mathrm{kg} / \mathrm{min}$ for $60 \mathrm{~min}$ i.c.v. significantly potentiated the hypotensive and bradycardic effects of i.c.v. clonidine. Nicardipine, in a dose of $0.3 \mu \mathrm{g} / \mathrm{kg} / \mathrm{min}$ for $60 \mathrm{~min}$ i.c.v., attenuated the hypotensive and bradycardic effects of i.c.v. clonidine or B-HT 920, an $\alpha_{2}$-adrenoceptor agonist, in anesthetized rats, whereas it did not modify the cardiovascular effect of i.c.v. angiotensin II or $\gamma$-aminobutylic acid in conscious rats. Nicardipine, in a dose of $0.3 \mu \mathrm{g} / \mathrm{kg} / \mathrm{min}$ for $60 \mathrm{~min}$ i.v., did not modulate the hypotensive and bradycardic effects of i.c.v. clonidine. 3-Isobutyl-lmethylxanthine (IBMX), a cyclic AMP phosphodiesterase inhibitor, in a dose of 3 $\mu \mathrm{g} / \mathrm{kg} / \mathrm{min}$ for $60 \mathrm{~min}$ i.c.v., also attenuated the hypotensive and bradycardic effects of i.c.v. clonidine. Potentiation by the three i.c.v. Ca-antagonists of the hypotensive and bradycardic effects of clonidine would be explainable if their inhibitory effect on Ca-influx is exerted at presynaptic nerve terminals but not at postsynaptic. The mechanisms of the cardiovascular effect of i.c.v. Ca-antagonists still remain to be elucidated but may be independent of a central $\alpha_{2}$-adrenoceptor mechanism. Dihydropyridine Ca-antagonists like nicardipine are also potent inhibitor of cyclic AMP phosphodiesterase. Since IBMX mimicked the effect of nicardipine, the effect of a low dose of i.c.v. nicardipine in attenuating the hypotensive and bradycardic effects of i.c.v. clonidine may be mediated by inhibition of cyclic AMP phosphodiesterase in the central nervous system. clonidine ; IBMX ; central nervous system; blood pressure; pulse rate

Received June 21, 1986; accepted for publication December 1, 1986. 
Calcium entry blockers or calcium antagonists (Ca-antagonists) are currently available as antianginal and antihypertensive drugs. They are also capable of interfering with calcium-dependent neurotransmitter release from the peripheral neurons, although rather high concentrations were needed to achieve this neuronal suppression (Starke and Schümann 1973; Göthert et al. 1979). So far as central neurons are concerned, the Ca-antagonists, methoxyverapamil (D 600) and diltiazem, have been reported to reduce markedly the depolarization-induced, calciumdependent release of ${ }^{3} \mathrm{H}$-catecholamines from guinea-pig brain vesicular preparations (Ebstein and Daly 1982). Therefore, it can be expected that Ca-antagonists, when applied to the central nervous system (CNS), would produce some centrallymediated effects. Nevertheless, such information is very scarce in the literature. A pertinent paper written by Timmermans et al. (1983) has come to our attention. In their study, nifedipine, a Ca-antagonist, when applied intracerebroventricularly (i.c.v.) to rats, antagonized the hypotensive effect of i.c.v. clonidine, an $\alpha_{2}$-adrenoceptor agonist. However, it did not discuss the nifedipine's central effects on cardiovascular functions in any detail. More recently Higuchi et al. (1985) reported that verapamil, diltiazem or nifedipine produced hypotension and bradycardia when these agents were administered into the nucleus tractus solitarii (NTS) or its vicinity, where the site of action of $\alpha_{2}$-adrenoceptor agonist is postulated. It is well known that $\alpha_{2}$-adrenoceptors play a key role in mediating the hypotensive and bradycardic effects of centrally acting antihypertensive drugs such as clonidine (Kobinger and Pichler 1980; Timmermans et al. 1981). A close relation has been postulated to exist between $\alpha_{2}$-adrenoceptors and the Ca-channel particularly at the postsynaptic sites in the CNS. In view of these opinions the interaction between $\mathrm{Ca}$-antagonists and $\alpha_{2}$-adrenoceptor agonists was investigated in the present study. In addition we designed the present study to obtain information about the centrally mediated cardiovascular effects of Ca-antagonists. For this purpose we administered Ca-antagonists centrally and compared the results with those obtained by their intravenous (i.v.) administration. As the chemical structures of Ca-antagonists are diverse, some of them have additional actions such as an inhibition on the fast Na-channel (Fleckenstein 1981). Therefore, to find out the effect ascribable to the Ca-antagonism, in the present study we chose three structurally different Ca-antagonists, i.e., verapamil, diltiazem and nicardipine.

\section{Material and Methods}

Male Sprague-Dowley rats of 200-400 g (15-25 weeks) were used. These animals were anesthetized with sodium pentobarbital (Nembutal ${ }^{\circledR}$, Abbott) and i.c.v. cannulas made of polyethylene tubing were implanted stereotaxically into both cerebroventricles at coordinates AP 1.0, L and R 1.5, H 5.0 with the bregma as reference. A week later catheters were implanted in the left femoral artery and vein, and passed subcutaneously to emerge at the neck. The catheters were filled with heparinized saline $(1,000 \mathrm{IU} / \mathrm{ml})$ and sealed by heating. The animals were allowed to recover for at least $24 \mathrm{hr}$ and were conscious or 
anesthetized during subsequent studies. During each experiment on conscious rats, rats were placed in rectangular boxes $30 \times 17 \times 17(\mathrm{~cm})$ without any restriction of movement. Blood pressure was recorded from the femoral artery using a pressure transducer (Statham, P23ID, Oxnard, CA, USA) and pulse rate (PR) was measured using a cardiotachometer (Nihon Kohden, RT-5, Tokyo). Pulsatile arterial pressure, mean arterial pressure (MAP) and PR were recorded continuously on a rectilinear recorder (San-Ei Instrument, Type BK 12, Tokyo). At least $1 \mathrm{hr}$ was allowed for stabilization of the blood pressure and PR before starting experiments on conscious rats. By this time the rats became generally resting.

The drugs used in the present study were clonidine hydrochrolide (Boehringer Ingelheim, Ingelheim, FRG), B-HT 920 (Dr. Karl Thomae, Biberach an der Riss, FRG), angiotensin II (Hypertensin ${ }^{\circledR}$, Ciba-Geigy, Basel, Switzerland), $\gamma$-aminobutyric acid (GABA, Sigma, St. Louis, MO, USA), (-)-verapamil hydrochloride (Knoll, Ludwigshafen, FRG), diltiazem hydrochloride (Tanabe, Osaka), nicardipine hydrochloride (Yamanouchi, Tokyo) and 3-isobutyl-1-methylxanthine (IBMX, Sigma). All the drugs were dissolved in physiological saline.

Intracerebroventricular injections were made in a volume less than $10 \mu \mathrm{l}$ in $4 \mathrm{sec}$, and i.c.v. infusions were made at a rate of less than $1 \mu \mathrm{l} / \mathrm{min}$ using an infusion pump (Princeton Medical Instrument, Model 575, Natic, MA, USA). Intravenous infusions of drugs were made through the implanted venous catheter at a rate of less than $10 \mu \mathrm{l} / \mathrm{min}$. Postmortem examination of the brain was performed to verify the position of i.c.v. cannulas.

\section{Experimental protocol}

Experiments were done as described below. In experiments testing the drug interaction all comparisons were done within the same animals.

\section{Experiment 1. Cardiovascular effects of i.c.v. and i.v. Ca-antagonists}

In conscious rats verapamil, diltiazem and nicardipine were infused i.c.v. at rates of $0.3,1$ and $3 \mu \mathrm{g} / \mathrm{kg} / \mathrm{min}$ for $30 \mathrm{~min}$ and cardiovascular responses to these drugs were examined. Doses were increased in a cummulative manner. The effect of the same amount of i.c.v. saline was also tested as a control.

In conscious rats nicardipine was also infused i.v. in doses of $0.3,1,3,10$ and $30 \mu \mathrm{g} /$ $\mathrm{kg} / \mathrm{min}$ for $10 \mathrm{~min}$ and their cardiovascular effects were examined.

Experiment 2. Effects of Ca-antagonists on cardiovascular responses to i.c.v. clonidine

The effects of $\mathrm{Ca}$-antagonists on cardiovascular responses to i.c.v. clonidine were examined. Since previous experiments showed that the cardiovascular effects of i.c.v. clonidine in conscious rats were minimal (Imai et al. 1986), the experiments were done on anesthetized rats, unless otherwise stated. In this series of experiments, an i.c.v. infusion of each Ca-antagonist at a rate of 0.3 or $3 \mu \mathrm{g} / \mathrm{kg} / \mathrm{min}$ was started $60 \mathrm{~min}$ before an i.c.v. injection of clonidine and continued until the effect of clonidine disappeared in anesthetized rats. The dose of each Ca-antagonist infused at a rate of 0.3 or $3 \mu \mathrm{g} / \mathrm{kg} / \mathrm{min}$ for 60 min was termed as "low dose" or "high dose" of Ca-antagonist, respectively. At least 24 $\mathrm{hr}$ were allowed to elapse between the experiment with and without Ca-antagonist and the order was randomized.

2-1. The dose-response relationship for i.c.v. clonidine in doses of 1,3 and $10 \mu \mathrm{g} / \mathrm{kg}$ was examined with and without i.c.v. nicardipine. In the absence of nicardipine, the first dose $(1 \mu \mathrm{g} / \mathrm{kg})$ of clonidine was injected i.c.v. $15 \mathrm{~min}$ after pentobarbital $(50 \mathrm{mg} / \mathrm{kg}$ i.p. $)$. Its second dose $(3 \mu \mathrm{g} / \mathrm{kg}$ i.c.v. $)$ was administered $2 \mathrm{hr}$ after the first one, and $24 \mathrm{hr}$ were allowed to pass before the third dose (10 $\mu \mathrm{g} / \mathrm{kg}$ i.c.v.). The rats were anesthetized again before $10 \mu \mathrm{g} / \mathrm{kg}$ clonidine. Before or after the experiment in the absence of nicardipine, the low dose or the high dose of nicardipine was infused i.c.v. in anesthetized rats. The remaining procedures except nicardipine infusion were the same as those in the experiments without nicardipine. To maintain the stable anesthesia, pentobarbital (10 mg/kg i.p.) was 
supplemented any time as needed.

2-2. The effects of verapamil and diltiazem on the cardiovascular responses to i.c.v. clonidine $(10 \mu \mathrm{g} / \mathrm{kg})$ were examined in anesthetized rats. Before or after the experiment without Ca-antagonist, verapamil or diltiazem in the low or the high dose was infused i.c.v. and the effect of i.c.v. clonidine was examined during infusion of each Ca-antagonist in a similar way to $2-1$.

2-3. The effect of the high dose of i.c.v. nicardipine on the cardiovascular responses to i.c.v. clonidine in a dose of $30 \mu \mathrm{g} / \mathrm{kg}$ was examined also in conscious rats.

2-4. In anesthetized rats the effect of i.v. nicardipine on the cardiovascular responses to i.c.v. clonidine was examined. In experiments with i.v. nicardipine, the infusion of this drug at a rate of $0.3 \mu \mathrm{g} / \mathrm{kg} / \mathrm{min}$ was started before clonidine $(10 \mu \mathrm{g} / \mathrm{kg})$ injection and continued until the effect of the latter disappeared. The ramaining procedures were the same as in $2-1$.

Experiment 3. Effects of nicardipine on the cardiovascular responses to several centrally acting drugs

Since the effect of the low dose of i.c.v. nicardipine on cardiovascular responses to i.c.v. clonidine was different from that of other Ca-antagonists, its effects on cardiovascular responses to other drugs administered i.c.v. were investigated. At least $24 \mathrm{hr}$ were allowed to elapse between the experiments with and without Ca-antagonist, and the order was randomized.

3-1. The dose-response relationships for cardiovascular action of i.c.v. B-HT 920, a selective $\alpha_{2}$-adrenoceptor agonist, in doses of 1,3 and $10 \mu \mathrm{g} / \mathrm{kg}$ were examined with and without the low dose of i.c.v. nicardipine in anesthetized rats. The procedures were the same as in $2-1$.

3-2. The dose-response relationships for cardiovascular action of i.c.v. angiotensin II in doses of 30,100 and $300 \mathrm{ng} / \mathrm{kg}$, and i.c.v. GABA in doses of 450,900 and $1,800 \mu \mathrm{g} / \mathrm{kg}$ were examined with and without the low dose of i.c.v. nicardipine in conscious rats.

3-3. The cardiovascular effect of i.c.v. clonidine in a dose of $10 \mu \mathrm{g} / \mathrm{kg}$ was examined with and without i.c.v. IBMX, a cyclic AMP phosphodiesterase inhibitor, in a dose of $3 \mu \mathrm{g} /$ $\mathrm{kg} / \mathrm{min}$ for $60 \mathrm{~min}$ in anesthetized rats. The remaining procedures were the same as in 22. In the separate experiments, the cardiovascular effect of i.c.v. IBMX was also examined in 6 conscious rats.

\section{Statistical analysis}

All values are given in terms of mean \pm s.E., unless otherwise stated. Dose-response curves were compared by analysis of covariance. Difference of time course within animals was compared using three-way analysis of variance. The remaining cardiovascular responses within animals were analyzed using Student's $t$-test for paired comparison.

\section{Results}

\section{Experiment 1}

MAP and PR just preceding Ca-antagonist infusion are presented in Table 1.

In conscious rats all the three $\mathrm{Ca}$-antagonists, i.e., verapamil, diltiazem and nicardipine, administered i.c.v. in doses of $0.3,1$ and $3 \mu \mathrm{g} / \mathrm{kg} / \mathrm{min}$ for $30 \mathrm{~min}$, induced dose-dependent increases in MAP and PR (Fig. 1), whereas i.c.v. infusion of saline induced no significant change in these variables. The hypertensive and tachycardiac responses to the Ca-antagonists developed slowly and reached their respective peak values $10-15$ min after the start of the infusion. As seen in Fig. 1 , the dose-response curves for increase in MAP and PR produced by the three 
TABLE 1. Mean arterial pressure $(M A P)$ and pulse rate $(P R)$ just before i.c.v. infusion of Ca-antagonist

\begin{tabular}{lccc}
\hline \multicolumn{1}{c}{ Drugs } & $n$ & $\begin{array}{c}\mathrm{MAP} \\
(\mathrm{mm} \mathrm{Hg})\end{array}$ & $\begin{array}{c}\mathrm{PR} \\
\text { (beats } / \mathrm{min})\end{array}$ \\
\hline Verapamil i.c.v. & 6 & $99.1 \pm 6.6$ & $380 \pm 25$ \\
Diltiazem i.c.v. & 5 & $95.3 \pm 7.1$ & $385 \pm 27$ \\
Nicardipine i.c.v. & 8 & $101.5 \pm 25.3$ & $391 \pm 91$ \\
Nicardipine i.v. & 6 & $102.3 \pm 7.8$ & $397 \pm 29$ \\
\hline
\end{tabular}

Values are given in terms of mean \pm s.D.

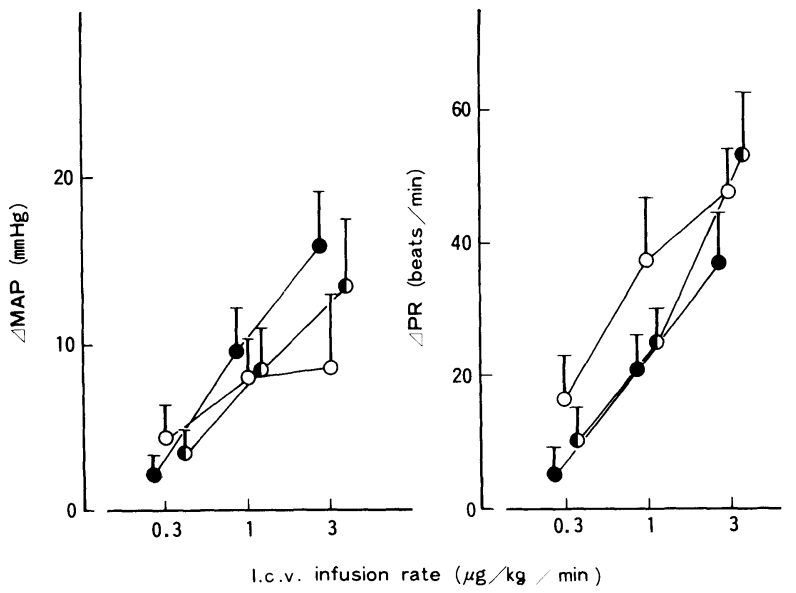

Fig. 1. Dose-response relationships for hypertensive and tachycardiac effects of nicardipine $(\bigcirc, n=8)$, diltiazem $(\bullet, n=5)$ and verapamil $(\bullet, n=6)$, administered intracerebroventricularly (i.c.v.). Abbreviations: $\triangle \mathrm{MAP}$, change in mean arterial pressure; $\triangle \mathrm{PR}$, change in pulse rate. Abbreviations are the same in the following figures.

Ca-antagonists were not significantly different from each other.

Nicardipine administered i.v. in doses of 3,10 and $30 \mu \mathrm{g} / \mathrm{kg} / \mathrm{min}$ for $10 \mathrm{~min}$ caused a decrease in MAP and an increase in PR in a dose-dependent manner, whereas doses lower than $1 \mu \mathrm{g} / \mathrm{kg} / \mathrm{min}$ for $10 \mathrm{~min}$ had no effect on these variables.

\section{Experiment 2}

In 6 rats the changes in MAP and $\mathrm{PR}$ after the pentobarbital anesthesia were followed. Fifteen min after i.p. injection of pentobarbital $(50 \mathrm{mg} / \mathrm{kg})$, MAP fell to its nadir, then gradually recovered. Seventy-five min after the anesthesia MAP was significantly higher than that 15 min after anesthesia $(p<0.05$ vs. nadir). The PR at 15 min after pentobarbital injection was significantly lower than that $75 \mathrm{~min}$ after pentobarbital injection $(p<0.05)$.

Clonidine administered i.c.v. (1, 3 and $10 \mu \mathrm{g} / \mathrm{kg})$ induced biphasic changes in $\mathrm{MAP}$ and $\mathrm{PR}$; initial hypotension and bradycardia followed by slight hyperten- 
TABLE 2. Mean arterial pressure $(M A P)$ and pulse rate $(P R)$ just before i.c.v. injection of clonidine in the experiments with and without Ca-antagonist treatment

\begin{tabular}{|c|c|c|c|c|c|c|c|}
\hline & \multirow{2}{*}{$\begin{array}{l}\text { Exp. No. } \\
\text { Treatment }\end{array}$} & \multirow{2}{*}{$\begin{array}{c}\text { Dose } \\
(\mu \mathrm{g} / \mathrm{kg} / \\
\min )\end{array}$} & \multirow[b]{2}{*}{$n$} & \multicolumn{2}{|c|}{ MAP (mm Hg) } & \multicolumn{2}{|c|}{ PR (beats/min) } \\
\hline & & & & $\begin{array}{l}\text { Without } \\
\text { treatment }\end{array}$ & $\begin{array}{l}\text { With } \\
\text { treatment }\end{array}$ & $\begin{array}{l}\text { Without } \\
\text { treatment }\end{array}$ & $\begin{array}{l}\text { With } \\
\text { treatment }\end{array}$ \\
\hline \multirow{2}{*}{$2-1$} & \multirow{2}{*}{$\begin{array}{l}\text { Nicardipine } \\
\text { i.c.v. }\end{array}$} & 0.3 & 6 & $92.0 \pm 6.1$ & $91.8 \pm 12.9$ & $419 \pm 22$ & $413 \pm 54$ \\
\hline & & 3.0 & 8 & $77.0 \pm 17.5$ & $87.1 \pm 20.4^{*}$ & $351 \pm 28$ & $451 \pm 48^{* *}$ \\
\hline \multirow{2}{*}{\multicolumn{2}{|c|}{$\begin{array}{l}\text { Verapamil } \\
\text { i.c.v. }\end{array}$}} & 0.3 & 8 & $92.6 \pm 11.6$ & $100.9 \pm 20.3$ & $399 \pm 28$ & $401 \pm 31$ \\
\hline & & 3.0 & 6 & $83.0 \pm 13.2$ & $89.3 \pm 11.8$ & $365 \pm 42$ & $448 \pm 37^{*}$ \\
\hline \multirow[t]{2}{*}{$2-2$} & Diltiazem & 0.3 & 7 & $99.0 \pm 10.0$ & $100.0 \pm 13.4$ & $393 \pm 21$ & $424 \pm 58$ \\
\hline & L i.c.v. & 3.0 & 8 & $77.9 \pm 11.0$ & $92.1 \pm 10.7^{*}$ & $353 \pm 42$ & $435 \pm 51^{*}$ \\
\hline $2-3$ & $\begin{array}{l}\text { Nicardipine } \\
\text { i.c.v. }\end{array}$ & 3.0 & 8 & $103.5 \pm 7.1$ & $105.3 \pm 14.9$ & $395 \pm 31$ & $441 \pm 59$ \\
\hline $2-4$ & $\begin{array}{l}\text { Nicardipine } \\
\text { i.v. }\end{array}$ & 0.3 & 6 & $83.0 \pm 13.2$ & $76.7 \pm 8.0$ & $365 \pm 42$ & $395 \pm 34$ \\
\hline
\end{tabular}

Values are given in terms of mean \pm s.D.

${ }^{*} p<0.05,{ }^{* *} p<0.01$. against without treatment.

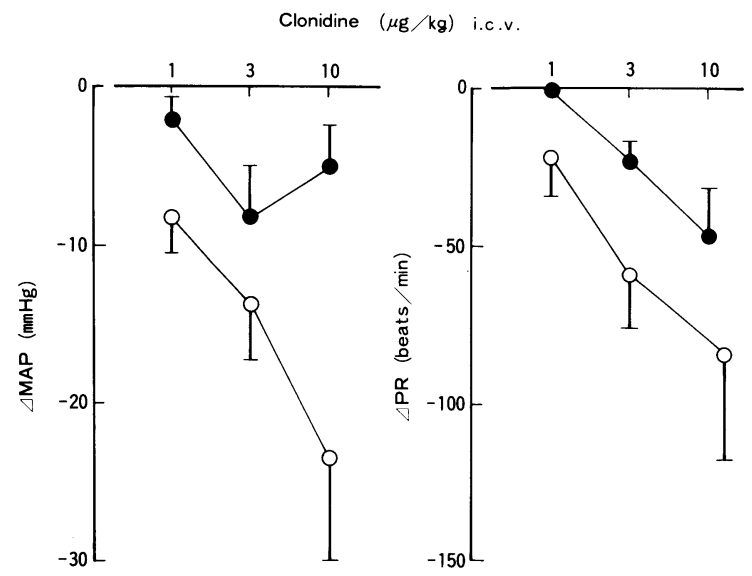

Fig. 2. Dose-response relationships for the hypotensive and bradycardic effects of i.c.v. clonidine. Open symbols refer to the control responses $(n=6)$. Solid symbols refer to the responses during i.c.v. infusion of nicardipine at a rate of $0.3 \mu \mathrm{g} / \mathrm{kg} / \mathrm{min}$ for $60 \mathrm{~min}(n=6)$.

sion and tachycardia. Since the control experiments for pentobarbital anesthesia showed gradual increases in MAP and PR, the data concerning hypertensive and tachycardiac effects of i.c.v. clonidine were discarded from the present results. MAP and PR just preceding i.c.v. injection of clonidine $(0.3 \mu \mathrm{g} / \mathrm{kg})$ were presented in Table 2.

2 -1. As shown in Fig. 2 , the hypotensive $\left(\mathrm{F}_{1,35}=9.50, p<0.01\right)$ and bradycardic $\left(\mathrm{F}_{1,35}=5.21, p<0.05\right)$ effects of i.c.v. clonidine were significantly attenuated by the low dose of i.c.v. nicardipine. On the contrary, the high dose of nicardipine significantly potentiated the hypotensive $\left(F_{1,47}=61.77, p<0.01\right)$ 


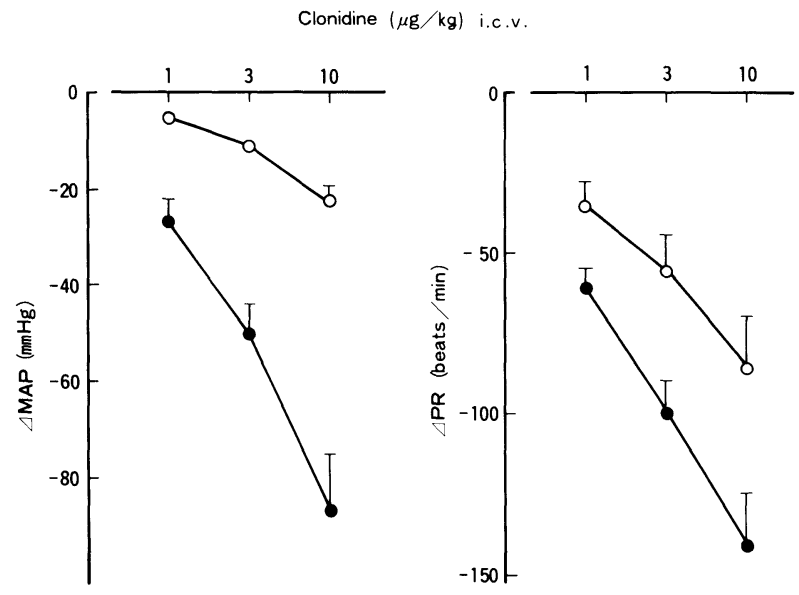

Fig. 3. Dose-response relationships for the hypotensive and bradycardic effects of i.c.v. clonidine. Open symbols refer to the control responses $(n=8)$. Solid symbols refer to the responses during i.c.v. infusion of nicardipine at a rate of $3 \mu \mathrm{g} / \mathrm{kg} / \mathrm{min}$ for $60 \mathrm{~min}(n=8)$.

TABLE 3. Effects of Ca-antagonist on cardiovascular effects of i.c.v. clonidine $(10 \mu \mathrm{g} / \mathrm{kg})$

\begin{tabular}{|c|c|c|c|c|c|c|}
\hline \multirow[b]{2}{*}{ Treatment } & \multirow{2}{*}{$\begin{array}{c}\text { Dose } \\
(\mu \mathrm{g} / \mathrm{kg} / \\
\mathrm{min})\end{array}$} & \multirow[b]{2}{*}{$n$} & \multicolumn{2}{|c|}{$\triangle \mathrm{MAP}(\mathrm{mm} \mathrm{Hg})$} & \multicolumn{2}{|c|}{$\triangle \mathrm{PR}$ (beats $/ \mathrm{min})$} \\
\hline & & & $\begin{array}{l}\text { Without } \\
\text { treatment }\end{array}$ & $\begin{array}{l}\text { With } \\
\text { treatment }\end{array}$ & $\begin{array}{l}\text { Without } \\
\text { treatment }\end{array}$ & $\begin{array}{l}\text { With } \\
\text { treatment }\end{array}$ \\
\hline \multirow[t]{3}{*}{ Verapamil } & 0.3 & 8 & $-24.1 \pm 4.7$ & $-26.1 \pm 5.0$ & $-106 \pm 18$ & $-114 \pm 23$ \\
\hline & 3.0 & 6 & $-24.2 \pm 4.3$ & $-34.2 \pm 3.8^{*}$ & $-100 \pm 13$ & $-123 \pm 14$ \\
\hline & $(\%$ & hange) & $(-28.0 \pm 3.2)$ & $(-38.5 \pm 3.9)$ & $(-27.2 \pm 3.6)$ & $(-29 \pm 2.4)$ \\
\hline \multirow[t]{3}{*}{ Diltiazem } & 0.3 & 7 & $-31.1 \pm 4.8$ & $-26.9 \pm 2.8$ & $-109 \pm 20$ & $-101 \pm 12$ \\
\hline & 3.0 & 8 & $-15.8 \pm 2.7$ & $-27.4 \pm 2.0$ & $-79 \pm 9$ & $-114 \pm 8$ \\
\hline & $(\%$ & hange & $(-18.5 \pm 3.7)$ & $(-30.1 \pm 2.5)^{*}$ & $(-21.6 \pm 2.0)$ & $(-23.4 \pm 3.6)$ \\
\hline \multirow[t]{3}{*}{ Nicardipine } & 0.3 & 6 & $-23.5 \pm 6.6$ & $-5.0 \pm 2.6^{* *}$ & $-84 \pm 3$ & $-47 \pm 17^{*}$ \\
\hline & 3.0 & 8 & $-20.4 \pm 2.8$ & $-34.1 \pm 4.6^{* *}$ & $-87 \pm 12$ & $-141 \pm 16^{* *}$ \\
\hline & $(\%$ & hange & $(-27.1 \pm 4.1)$ & $(-40.6 \pm 5.4)^{*}$ & $(-25.0 \pm 3.4)$ & $(-31.6 \pm 3.6)^{*}$ \\
\hline
\end{tabular}

Values are given in terms of mean \pm S.E. ${ }^{*} p<0.05,{ }^{* *} p<0.01$ against without treatment. Without treatment, the change in MAP $(\triangle \mathrm{MAP})$ and $\mathrm{PR}(\Delta \mathrm{PR})$ induced by i.c.v. clonidine in the experiment without i.c.v. Ca-antagonist. With treatment, the change in MAP and PR induced by i.c.v. clonidine during infusion of $\mathrm{Ca}$ antagonist. \% change, percent changes in MAP and PR induced by i.c.v. clonidine with and without high dose of each $\mathrm{Ca}$-antagonist.

and bradycardic $\left(F_{1,47}=20.17, p<0.01\right)$ effects of i.c.v. clonidine (Fig. 3).

2-2. Verapamil and diltiazem infused i.c.v. in the low dose did not modulate the cardiovascular effects of i.c.v. clonidine $(10 \mu \mathrm{g} / \mathrm{kg})$, whereas their high dose significantly potentiated the hypotensive effect of i.c.v. clonidine ( $10 \mu \mathrm{g} / \mathrm{kg})$ (Table 3). Bradycardia induced by i.c.v. clonidine was also significantly 


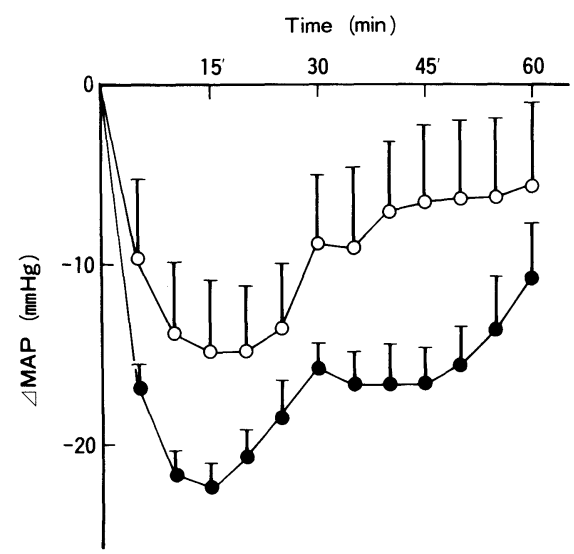

Fig. 4. The time course of hypotensive effect of i.c.v. clonidine in conscious rats. Open symbols refer to the control responses. Solid symbols refer to the responses during i.c.v. infusion of nicardipine at a rate of $3 \mu \mathrm{g} / \mathrm{kg} / \mathrm{min}$ for 60 $\min (n=8)$.

potentiated by the high dose of i.c.v. diltiazem (Table 3). Percent changes in MAP and PR induced by i.c.v. clonidine in experiments without Ca-antagonist were also compared with those during infusion of the high dose of each Caantagonist. As shown in Table 3, percent decreases in MAP during infusion of Ca-antagonists were still significantly greater than those in experiments without Ca-antagonist whereas only percent decreases in $\mathrm{PR}$ during nicardipine infusion were significantly greater than those in experiments.

$2-3$. The cardiovascular effects of i.c.v. clonidine $(30 \mu \mathrm{g} / \mathrm{kg})$ with and without the high dose of i.c.v. nicardipine were also examined in conscious rats. The hypotensive effect of i.c.v. clonidine during nicardipine infusion was significantly greater than that in the experiment without nicardipine also in conscious rats (Fig. 4, $\mathrm{F}_{1,191}=31.03, p<0.01$ ), whereas changes in $\mathrm{PR}$ during nicardipine infusion were not significantly different from those in the experiment without nicardipine.

2-4. Nicardipine administered i.v. in a dose of $0.3 \mu \mathrm{g} / \mathrm{kg} / \mathrm{min}$ for $60 \mathrm{~min}$ did not modulate the hypotension $(-24.2 \pm 4.3 \mathrm{vs} .-20.3 \pm 2.7 \mathrm{mmHg})$ and bradycardia $(-101 \pm 13$ vs. $-113 \pm 15$ beats $/ \mathrm{min})$ induced by $10 \mu \mathrm{g} / \mathrm{kg}$ of i.c.v. clonidine.

\section{Experiment 3}

MAP and PR just preceding i.c.v. injection of B-HT 920, angiotensin II, GABA or clonidine each in the minimal dose are presented in Table 4.

3-1. B-HT $920 \quad(1,3$ and $10 \mu \mathrm{g} / \mathrm{kg})$ administered i.c.v. caused dosedependent hypotension and bradycardia. The onset of cardiovascular action of i.c.v. B-HT 920 was more rapid than that of i.c.v. clonidine. As shown in Fig. 5, the low dose of i.c.v. nicardipine significantly attenuated the hypotension $\left(F_{1,35}=\right.$ 
TABLE 4. Mean arterial pressure $(M A P)$ and pulse rate $(P R)$ just before i.c.v. injection of B-HT 920, angiotensin II, GABA or clonidine in the experiments with and without nicardipine or IBM

\begin{tabular}{ccccccccc}
\hline $\begin{array}{c}\text { Exp. No. } \\
\text { Treatment }\end{array}$ & $\begin{array}{c}\text { Dose } \\
(\mu \mathrm{g} / \mathrm{kg} / \\
\mathrm{min})\end{array}$ & $n$ & & \multicolumn{2}{c}{ MAP $(\mathrm{mm} \mathrm{Hg})$} & & \multicolumn{2}{c}{ PR (beats/min) } \\
& & & Without & $\begin{array}{c}\text { With } \\
\text { treatment }\end{array}$ & & $\begin{array}{c}\text { Without } \\
\text { treatment } \\
\text { treatment }\end{array}$ & $\begin{array}{c}\text { With } \\
\text { treatment }\end{array}$ \\
\hline $3-1$ & $\begin{array}{c}\text { Nicardipine } \\
\text { i.c.v. }\end{array}$ & 0.3 & 6 & $108.0 \pm 17.6$ & $97.8 \pm 12.2$ & & $408 \pm 61$ & $420 \pm 47$ \\
$3-2-\begin{array}{c}\text { Nicardipine } \\
\text { i.c.v. } \\
\text { Nicardipine }\end{array}$ & 0.3 & 7 & $105.5 \pm 11.6$ & $107.2 \pm 14.6$ & $400 \pm 58$ & $405 \pm 50$ \\
i.c.v. & 0.3 & 6 & $111.3 \pm 7.1$ & $114.5 \pm 21.5$ & $403 \pm 38$ & $420 \pm 61$ \\
$3-3 \quad$ IBMX i.c.v. & 3.0 & 8 & $87.9 \pm 13.0$ & $88.3 \pm 21.5$ & $404 \pm 71$ & $410 \pm 28$ \\
\hline
\end{tabular}

Values are given in terms of mean \pm S.D.

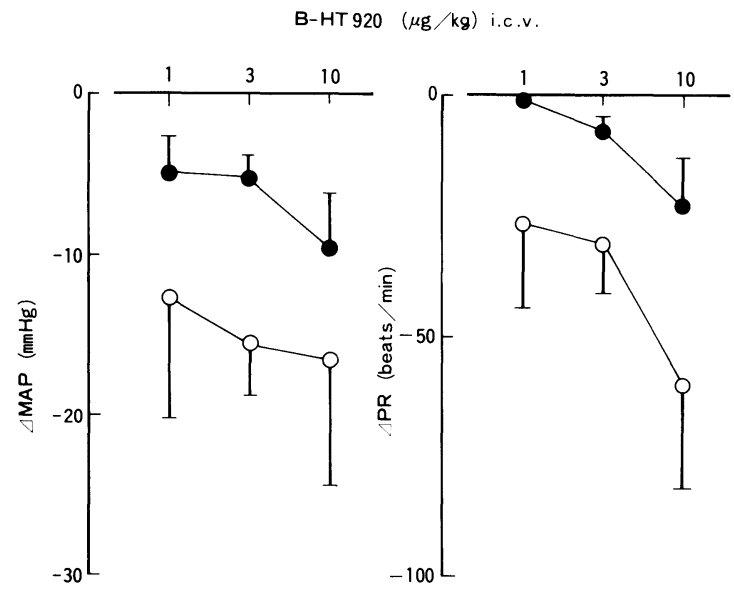

Fig. 5. Dose-response relationships for the hypotensive and tachycardic effects of i.c.v. B-HT 920. Open symbols refer to the control responses. Solid symbols refer to the responses during i.c.v. infusion of nicardipine at a rate of $0.3 \mu \mathrm{g} /$ $\mathrm{kg} / \mathrm{min}$ for $60 \min (n=6)$.

4.45, $p<0.05)$ and bradycardia $\left(F_{1,35}=7.82, p<0.01\right)$ induced by B-HT 920 .

3-2. Angiotensin II (30, 100 and $300 \mathrm{ng} / \mathrm{kg})$ administered i.c.v. induced dose-dependent hypertension and bradycardia. In 3 of 7 rats, bradycardia was followed by slight tachycardia. GABA $(450,900$ and $1,800 \mu \mathrm{g} / \mathrm{kg})$ administered i.c.v. induced dose-dependent hypotension and bradycardia, the latter being followed by tachycardia. The low dose of nicardipine administered i.c.v. did not modulate the cardiovascular actions of i.c.v. angiotensin II (Fig. 6) and GABA (Fig. 7).

3-3. Intracerebroventricular infusion of IBMX at a rate of $3 \mu \mathrm{g} / \mathrm{kg} / \mathrm{min}$ for

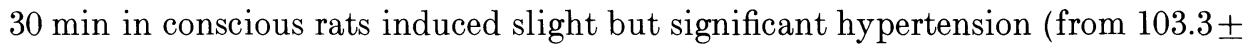




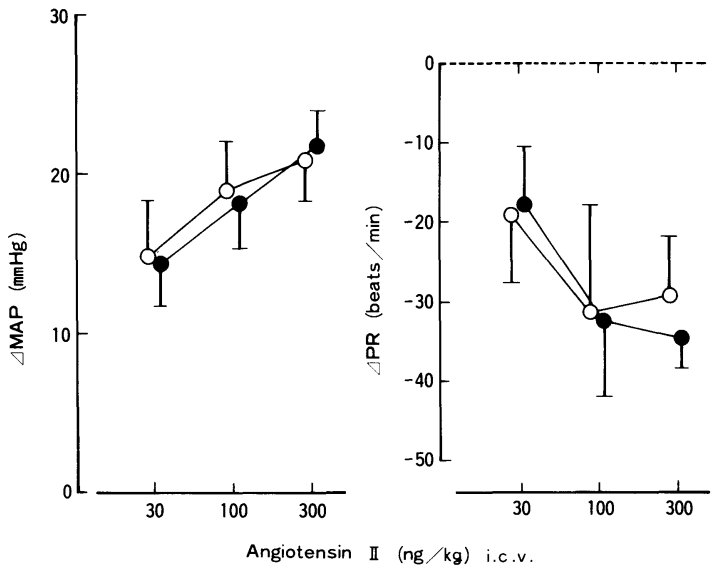

Fig. 6. Dose-response relationships for hypertensive and bradycardic effects of $i$. c.v. angiotensin II. Open symbols refer to the control responses. Solid symbols refer to the responses during i.c.v. infusion of nicardipine at a rate of $0.3 \mu \mathrm{g} / \mathrm{kg} / \mathrm{min}$ for $60 \mathrm{~min}(n=7)$.

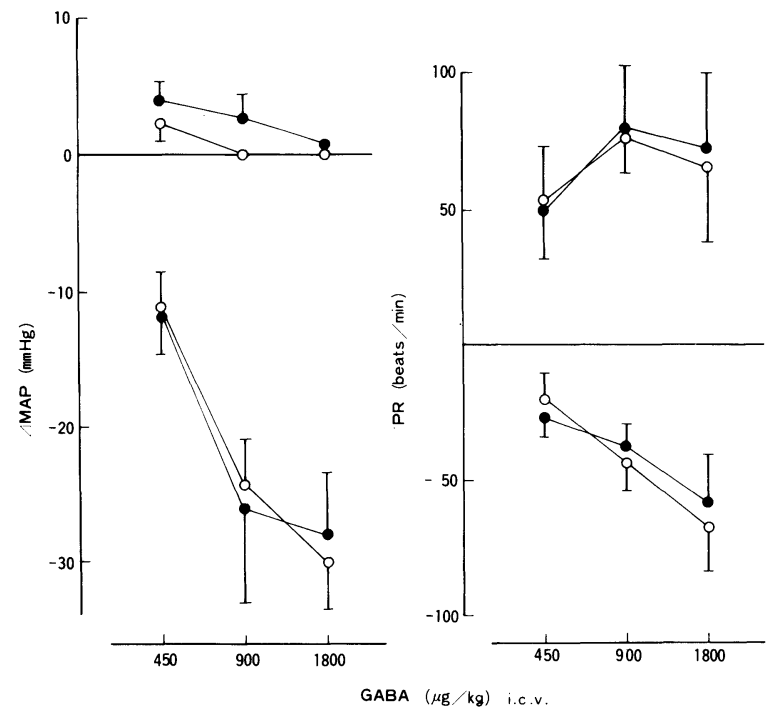

Fig. 7. Dose-response relationships for cardiovascular action of i.c.v. GABA. Open symbols refer to control response. Solid symbols refer to the responses during i.c.v. infusion of nicardipine at a rate of $0.3 \mu \mathrm{g} / \mathrm{kg} / \mathrm{min}$ for $60 \mathrm{~min}(n=$ $6)$.

14.8 to $107.3 \pm 12.1 \mathrm{mmHg}, p<0.05$ ) and tachycardia (from $370 \pm 42.4$ to $403 \pm 50.9$ beats $/ \mathrm{min}, p<0.01)$. However, in anesthetized rats MAP and PR during IBMX infusion were not significantly different from those in experiment without IBMX treatment (Table 4). The hypotensive and bradycardic effects of i.c.v. clonidine were significantly attenuated by centrally administered IBMX (Fig. 8). 

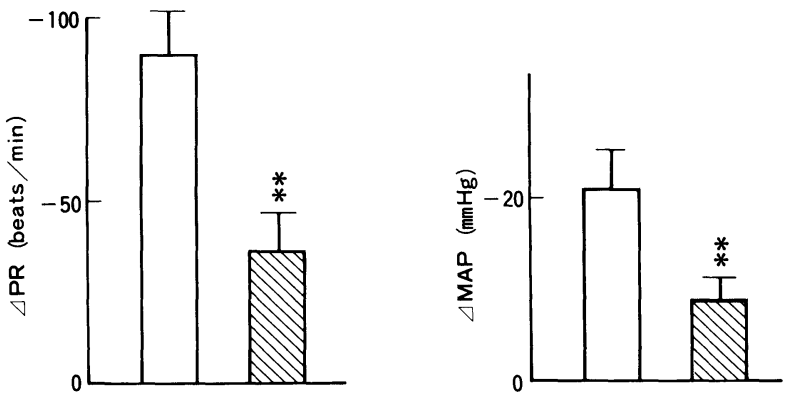

Fig. 8. Modification of the hypotensive and bradycardic effect of i.c.v. clonidine $(10 \mu \mathrm{g} / \mathrm{kg})$ by 3 -isobutyl methylxanthine (IBMX) administered i.c.v. at a rate of $3 \mu \mathrm{g} / \mathrm{kg} / \mathrm{min}$ for $60 \mathrm{~min}$. Open colum refers to the control responses. Hatched column refers to the responses during infusion of IBMX $(n=8)$.

${ }^{* *} p<0.01$ against control.

\section{Discussion}

The present study clearly demonstrated that the three structurally different Ca-antagonists, when administered i.c.v. in rats, all produced increases in MAP and PR. Their hypertensive effects are opposite to what these drugs produce when given i.v. Indeed, in the present study, too, i.v. nicardipine produced hypotension. Therefore, it is reasonable to conclude that the hypertensive and tachycardiac effects of the three Ca-antagonists administered i.c.v. are of central origin but not those which were produced by a fraction of the drugs that leaked into peripheral circulation. As their chemical structures vary, the three Caantagonists are different not only in potency or selectivity for vascular versus cardiac tissues (Taira 1979; Henry 1980) but also in action additional to Caantagonism. For example, diltiazem (Nakajima et al. 1975) and verapamil (Singh and Vaughan-Williams 1972 ; Bayer et al. 1975) in high concentrations have some blocking effects on the fast Na-channel, but not nicardipine (Iijima, Yanagisawa and Taira, personal communication). Therefore, the observed central hypertensive and tachycardiac effects of the three Ca-antagonists can not be attributed to such additional mechanisms of action but ascribed to Caantagonism. Here, the question arises how Ca-antagonism in the CNS results in hypertension and tachycardia. Recently Timmermans et al. (1983) have claimed that there would be a close relation in activation between $\alpha_{2}$-adrenoceptors at postsynaptic sites and the Ca-channel in the CNS as in peripheral vasculature. Their postulate was based on the findings that i.c.v. nifedipine inhibited the hypotensive effect of clonidine administered via the same route (i.c.v.). Thus, it may be reasonable to test whether the hypertensive and tachycardiac effects of the three Ca-antagonists would be explainable in terms of their inhibitory action on the Ca-channel activated following stimulation of postsynaptic $\alpha_{2}$-adrenoceptors. The present results, however, obtained with i.c.v. clonidine and the three i.c.v. 
Ca-antagonists were opposite to those reported by Timmermans et al. (1983) with i.c.v. clonidine and i.c.v. nifedipine. Diltiazem and verapamil in both the low and high doses, and nicardipine in the high dose given i.c.v. all failed to attenuate but instead potentiated the hypotensive and bradycardic effects of i.c.v. clonidine in anesthetized rats. Furthermore, the potentiation by the high dose of i.c.v. nicardipine of the hypotensive effect of clonidine was also observed in conscious rats although a much higher dose $(30 \mu \mathrm{g})$ of clonidine was needed to produce a sizable hypotensive effect. Thus, it is unlikely that the three Ca-antagonists produced the hypertensive and tachycardiac effects by inhibiting the Ca-channel closely associated with central postsynaptic $\alpha_{2}$-adrenoceptors as suggested by Timmermans et al. (1983). A new question arises what an alternative mechanism is.

Another postulation concerning the hypotensive and bradycardic effects of $\alpha_{2}$-adrenoceptor agonists is as follows : $\alpha_{2}$-adrenoceptors also exist at presynaptic sites, i.e., at nerve terminals in central noradrenergic neurons. Their activations result in a decrease in norepinephrine release which in turn results in the decreased activity in medullary facilitatory neurons and finally in the decreased sympathetic nerve activity (Van Zwieten et al. 1983). A decrease in $\mathrm{Ca}^{2+}$-availability through the Ca-channel for norepinephrine secretion has been postulated as the mechanism underlying presynaptic $\alpha$-adrenergic inhibition of norepinephrine release both in peripheral and in central noradrenergic neurons (Langer 1981; Starke 1981). If Ca-antagonists inhibit Ca-influx at presynaptic nerve terminals of central noradrenergic neurons, this would result in effects similar to those of $\alpha_{2}$-adrenoceptor agonists. Consequently, it is likely that Ca-antagonists would act synergistically with $\alpha_{2}$-adrenoceptor agonists, leading to the potentiation of the effects of the latter. Indeed, it has been shown that ${ }^{3} \mathrm{H}$-norepinephrine release from rat cortex synaptosomes is more susceptible to $\alpha$-adrenoceptor-mediated inhibition in the presence of increased concentrations of the inorganic Caantagonist, $\mathrm{Mg}^{2+}$ (DeLangen and Mulder 1980). Thus, as far as potentiation by the three i.c.v. Ca-antagonists of the hypotensive and bradycardic effects of clonidine is concerned, this appeared to be explainable if their inhibitory effect on Ca-influx at presynaptic nerve terminals is postulated. Recently Higuchi et al. (1985) reported that varapamil, diltiazem or nifedipine induced hypotension and bradycardia when these Ca-antagonists were administered into NTS or its vicinity and the effect of Ca-antagonist was blocked by 6-hydroxydopamine, suggesting that $\mathrm{Ca}$-antagonists act presynaptically at catecholaminergic nerve terminals in such loci. It is well known that NTS and its vicinity are responsible for the hypotensive and bradycardic effect of $\alpha_{2}$-adrenoceptor agonists (Kobinger and Pichler 1980; Timmermans et al. 1981). Thus, their results may also be explainable that Ca-antagonists induce hypotension and bradycardia through those modulatory effect on $\alpha_{2}$-adrenoceptor mechanism at NTS or its vicinity. Nevertheless, mechanisms responsible for their hypertensive and tachycardiac effects 
still remain to be elucidated.

In keeping with the results obtained with i.c.v. nifedipine by Timmermans et al. (1983), the low dose of i.c.v. nicardipine attenuated the hypotensive and bradycardic effects of i.c.v. clonidine. In this respect the low dose of nicardipine was of particular interest. Here, it should be recalled that nicardipine is not only a Ca-antagonist but also a potent inhibitor of cyclic AMP phosphodiastase (PDE) (Sakamoto et al. 1978; Nishikori et al. 1981). The involvement of PDE inhibition in the action of nicardipine has been demonstrated in rat uterine smooth muscle: When oxytocin-contracted uterine smooth muscle is relaxed by nicardipine, there is an increase in intracellular level of cyclic AMP (Nishikori et al. 1981). Therefore, it is tempting to postulate that the attenuation by the low dose of i.c.v. nicardipine of the hypotensive and bradycardic effects of i.c.v. clonidine is ascribed to its inhibitory action on PDE rather than to the action as a Ca-antagonist. In support for this possibility, i.c.v. IBMX caused an effect similar to that of the low dose of i.c.v. nicardipine. The potent inhibitory action of nifedipine on calmodulin-sensitive PDE has recently been reported but not of diltiazem and verapamil (Epstein et al. 1982 ; Norman et al. 1983). In addition Skolnick and Daly (1976) reported that clonidine can potentiate the effect of $\alpha$-adrenoceptor or $\beta$-adrenoceptor mediated elevation in adenylate cyclase activity in the cerebral cortex. Thus, the results obtained with i.c.v. nifedipine and clonidine by Timmermans et al. (1983) would be understandable. The question at the moment is not answered, however, why the dihydropyridine Ca-antagonists act as PDE inhibitors only in low concentrations.

The attenuation by the low dose of i.c.v. nicardipine was also seen in the cardiovascular effects of i.c.v. B-HT 920 but not of those of i.c.v. angiotensin II and GABA. Thus, the attenuating effect of the low dose of i.c.v. nicardipine was specific for the hypotension and bradycardia produced by $\alpha_{2}$-adrenoceptor stimulation. Interaction between PDE inhibitors and $\alpha_{2}$-adrenoceptor agonists to attenuate the effect of each has been shown from the level of behavior (Grant and Redmond 1982) to that of single neuronal activity (Matsui and Yamamoto 1984). The attenuation of the hypotensive and bradycardic effects of clonidine by IBMX and the low dose of nicardipine would be a phenomenon between the two extreme levels. However, it is worthy of considering that IBMX is known to possess a variety of actions in the brain besides PDE inhibition. The possibility remains that an interaction between clonidine and IBMX may occur at other sites.

After all in the present study we could not elucidate the site and mechanism responsible for the hypertensive and tachycardiac effect of Ca-antagonists. However, when the present results are compared with the recent results obtained by Higuchi et al. (1985), it is apparent that hypertension and tachycardia induced by Ca-antagonists are produced by their action on sites other than NTS or its vicinity. As their chemical structures vary, the three $\mathrm{Ca}$-antagonists act with different potencies. Nevertheless, in the present study three structurally diver- 
gent Ca-antagonists revealed equal potency for producing pressor and tachycardiac response when administered centrally. Thus, it is also possible that their hypertensive and tachycardiac effects are mediated by their unknown but common feature other than Ca-antagonism.

Finally, the clinical relevance of the present results should be referred. It has been reported that the tolerance to the hypotensive effect of nifedipine readily developed when nifedipine alone was administered to hypertensive patients, and that not only the hypotensive effect of nifedipine was greatly potentiated but also the development of tolerance was eliminated by combination of nifedipine with clonidine (Imai et al. 1980). The development of tolerance has been explained mainly by the volume expansion and reflexively-induced enhancement of sympathetic nerve activity. However, another explanation can be offered by the present results, i.e., the central hypertensive and tachycardiac effects of Caantagonists. The present results that the three Ca-antagonists potentiated the hypotensive and bradycardic effects of clonidine appear to provide an explanation for the potentiation and disappearance of development of tolerance in nifedipine effect by clonidine. Although in the present study it has not been examined whether the hypotensive effect of i.v. nifedipine is potentiated by i.c.v. clonidine, the potentiation of hypotensive effect of nifedipine by clonidine in the treatment of hypertension may also be explained by the central interaction of these drugs.

\section{Acknowledgments}

We grateful to Dr. Karl Thomae, Biberach an der Riss, Federal Republic of Germany, for a gift of B-HT 920, to Nippon Boehinger Ingelheim Co., Ltd, Kawanishi, Japan for clonidine, to Tanabe Seiyaku Co., Ltd., Osaka, Japan, for diltiazem, to Yamanouchi Pharmaceutical Co., Ltd., Tokyo, Japan, and to Eisai Co., Ltd., Tokyo, Japan for verapamil. We are also grateful to Miss Y. Takahira for typewriting the manuscript.

This study was supported by Grants from the Ministry of Education, Science and Culture of Japan (No. 59570350 and No. 6157041) and from Japan Research Foundation for Clinical Pharmacology.

\section{References}

1) Bayer, R., Kalusche, D., Kaufmann, R. \& Mannhold, R. (1975) Inotropic and electrophysiological actions of verapamil and D 600 in mammalian myocardium. III. Effects of the optical isomers on transmembrane action potentials. NaunynSchmiedeberg's Arch. Pharmacol., 290, 81-97.

2) DeLangen, C.D.J. \& Mulder, A.H. (1980) On the role of calcium ions in the presynaptic alpha-receptor mediated inhibition of $\left[{ }^{3} \mathrm{H}\right]$ noradrenaline release from rat brain cortex synaptosomes. Brain Res., 185, 399-408.

3) Ebstein, R.P. \& Daly, J.W. (1982) Release of norepinephrine and dopamine from brain vesicular preparations : Effects of calcium antagonists. Cell. molec. Neurobiol., 2, 205-213.

4) Epstein, P.M., Fiss, K., Hachisu, R. \& Andrenyak, D.M. (1982) Interaction of calcium antagonists with cyclic AMP phosphodiesterases and calmodulin. Biochem. biophys. Res. Commun., 105, 1142-1149.

5) Fleckenstein, A. (1981) Fundamental actions of calcium antagonists on myocardial 
and cardiac pacemaker cell membranes. In : New Perspectives on Calcium Antagonists, edited by G.B. Weiss, American Physiological Society, Bethesda, pp. 59-81.

6) Göthert, M., Nawrath, P. \& Neumeyer, H. (1979) Inhibitory effects of verapamil, prenylamine and D 600 on $\mathrm{Ca}^{2+}$-dependent noradrenaline release from the sympathetic nerves of isolated rabbit hearts. Naunyn-Schmiedeberg's Arch. Pharmacol., 310, 1119.

7) Grant, S.J. \& Redmond, D.E., Jr. (1982) Clonidine suppresses methylxanthine induced quasi-morphine withdrawal syndrome. Pharmacol. Biochem. Behav., 17, 655658.

8) Henry, P.D. (1980) Comparative pharmacology of calcium antagonists : Nifedipine, verapamil and diltiazem. Amer. J. Cardiol., 46, 1047-1058.

9) Higuchi, S., Takeshita, A., Ito, N., Imaizumi, T., Matsuguchi, H. \& Nakamura, M. (1985) Arterial pressure and heart rate responses to calcium channel blockers administered in the brainstem in rats. Circulat. Res., 57, 244-251.

10) Imai, Y., Abe, K., Otsuka, Y., Irokawa, N., Yasujima, M., Saito, K., Sakurai, Y., Chiba, S., Ito, T., Sato, M., Haruyama, T., Miura, Y. \& Yoshinaga, K. (1980) Management of severe hypertension with nifedipine in combination with clonidine or propranolol. Arzneimittel-Forsch., 30, 674-678.

11) Imai, Y., Nolan, P.L. \& Johnston, C.I. (1986) Tachycardic and hypertensive effects of centrally administered clonidine in conscious rats. Clin. exp. Hepertension, A8, 239-258.

12) Kobinger, W. \& Pichler, L. (1980) Relation between central sympathoinhibitory and peripheral pre- and postsynapticd -adrenoceptors as evaluated by different clonidinelike substances in rats. Naunyn-Schmiedeberg's Arch. Pharmacol., 315, 21-27.

13) Langer, S.Z. (1981) Presynaptic regulation of the release of catecholamines. Pharmacol. Rev., 32, 337-362.

14) Matsui, H. \& Yamamoto, C. (1984) The possible involvement of adenylate cyclase inhibition in the field potential suppression through alpha-2 adrenergic receptors in the bed nucleus of the stria terminalis. Brain Res., 293, 187-190.

15) Nakajima, H., Hoshiyama, M., Yamashita, K. \& Kiyomoto, A. (1975) Effect of diltiazem on electrical and mechanical activity of isolated cardiac ventricular muscle of guinea pig. Jap. J. Pharmacol., 25, 383-392.

16) Nishikori, K., Takenaka, T. \& Maeno, H. (1981) A possible mechanism for relaxation of rat uterine smooth muscle by nicardipine hydrochloride (YC-93). A new potent vasodilator. Jap. J. Pharmacol., 31, 701-709.

17) Norman, J.A., Ansell, J. \& Phillipps, M.A. (1983) Dihydropyridine Ca ${ }^{2+}$-entry blockers selectively inhibit peak I cAMP phosphodiesterase. Europ. J. Pharmacol., 93, 107-112.

18) Sakamoto, N., Terai, M., Takenaka, T. \& Maeno, H. (1978) Inhibition of cyclic AMP phosphodiesterase by 2, 6-dimethyl-4-(3-nitrophenyl)-1, 4-dihydropyridine-3, 5dicarboxylic acid 3-[2-(N-benzyl-N-methylamino $)]$ ethyl ester 5-methyl ester hydrochrolide (YC-93), a potent vasodilator. Biochem. Pharmacol., 27, 1269-1274.

19) Singh, B.N. \& Vaughan-Williams, E.M. (1972) Fourth class of anti-dysrhythmic action-Effect of verapamil on ouabain toxicity, on arterial and ventricular intracellular potentials, and on other features of cardiac function. Cardiovasc. Res., 6, 109119.

20) Skolnick, P. \& Daly, J.W. (1976) Interaction of clonidine with pre- and postsynaptic adrenergic receptors of rat brain : Effects on cyclic AMP-generating systems. Europ. J. Pharmacol., 39, 11-21.

21) Starke, K. (1981) Presynaptic receptors. Ann. Rev. Pharmacol. Toxicol., 21, 7-30.

22) Starke, K. \& Schümann, H.J. (1973) Wirkung von Nifedipine auf die Funktion der Sympathischen Nerven des Herzens. Arzeneimittel-Forsch., 23, 193-197.

23) Taira, N. (1979) Effects of diltiazem and other calcium-antagonists on cardiac 
functions and coronary blood flow as assessed in blood-perfused dog-heart preparations. In: New Drug Therapy with a Calcium Antagonist. Diltiazem Hakone Symposium '78, edited by R.J. Bing, Excerpta Medica, Amsterdam- Princeton, pp. 91103.

24) Timmermans, P.B.M.W.M., Schoop, A.M.C., Kwa, H.Y. \& VanZwieten, P.A. (1981) Characterization of $\alpha$-adrenoceptors participating in the central hypotensive and sedative effects of clonidine using yohimbine, rauwolscine and corynanthine. Europ. J. Pharmacol., 70, 7-15.

25) Timmermans, P.B.M.W.M., deJonge, A., vanMeel, J.C.A., Mathy, M-J. \& vanZwieten, P.A. (1983) Influence of nifedipine on functional responses in vivo initiated at $\alpha_{2}$-adrenoceptors. J. cardiovasc. Pharmacol., 5, 1-11.

26) Van Zwieten, P.A., Thoolen, M.J.M.C. \& Timmermans, P.B.M.W.M. (1983) The pharmacology of centrally acting antihypertensive drugs. Brit. J. clin. Pharmacol., 15, 455S-462S. 